\title{
əobserving the Tropical Atmosphere in Moisture Space
}

\author{
HAUKe SCHUlZ AND BJORN STEVENS \\ Max Planck Institute for Meteorology, Hamburg, Germany
}

(Manuscript received 3 December 2017, in final form 11 July 2018)

\begin{abstract}
Measurements from the Barbados Cloud Observatory are analyzed to identify the processes influencing the distribution of moist static energy and the large-scale organization of tropical convection. Five years of water vapor and cloud profiles from a Raman lidar and cloud radar are composed to construct the structure of the observed atmosphere in moisture space. The large-scale structure of the atmosphere is similar to that now familiar from idealized studies of convective self-aggregation, with shallow clouds prevailing over a moist marine layer in regions of low-rank humidity, and deep convection in a nearly saturated atmosphere in regions of high-rank humidity. With supplementary reanalysis datasets the overall circulation pattern is reconstructed in moisture space, and shows evidence of a substantial lower-tropospheric component to the circulation. This shallow component of the circulation helps support the differentiation between the moist and dry columns, similar to what is found in simulations of convective self-aggregation. Radiative calculations show that clearsky radiative differences can explain a substantial part of this circulation, with further contributions expected from cloud radiative effects. The shallow component appears to be important for maintaining the low gross moist stability of the convecting column. A positive feedback between a shallow circulation driven by differential radiative cooling and the low-level moisture gradients that help support it is hypothesized to play an important role in conditioning the atmosphere for deep convection. The analysis suggests that the radiatively driven shallow circulations identified by modeling studies as contributing to the self-aggregation of convection in radiative-convective equilibrium similarly play a role in shaping the intertropical convergence zone and, hence, the large-scale structure of the tropical atmosphere.
\end{abstract}

\section{Introduction}

Convective organization is almost synonymous with the broad field of mesoscale meteorology and phenomena such as sea- or land-breeze fronts, squall lines, hurricanes, or mesoscale convective systems (Houze 2004; Nakazawa 1988; Mapes and Houze 1993). But convective organization is also evident on much larger, synoptic, and even planetary scales, in the form of extratropical cyclones, the Madden-Julian oscillation (MJO) (Madden and Julian 1994), or even the intertropical convergence zone (ITCZ) (Raymond 2000). In many of these cases, clouds, as the visible manifestation of convection, can be thought of as being along for the ride-patterned by independently arising instabilities in the underlying flow. Squall lines are a well-studied

¿ Denotes content that is immediately available upon publication as open access.

Corresponding author: Hauke Schulz, hauke.schulz@mpimet. mpg.de counterexample to this idea, as the interaction of convection with the mean low-level shear leads to longerlived and larger-scale convective systems than would otherwise occur (Rotunno et al. 1988). Simulations of radiative-convective equilibrium (RCE) illustrate other ways in which convection can interact with the largescale flow, through its modulation by lower-tropospheric humidity, or by modifying surface fluxes or radiative heating, to organize, or self-aggregate (e.g., Tompkins 2001; Bretherton et al. 2005; Muller and Held 2012; Coppin and Bony 2015; Wing et al. 2017; Becker et al. 2017). These potential organization mechanisms have been hypothesized on the basis of model studies, and are thought to play a role in phenomena such as the MJO or the ITCZ (Arnold and Randall 2015) and possibly the properties of the climate system as a whole (Bony et al. 2015), but have not been widely studied with data.

The few studies that have used data to study convective aggregation have first focused on whether the hypothesized effects of convective aggregation can be observed in the present-day tropics. For instance, the aspect of convective self-aggregation that makes it 
potentially important for climate is its influence on the distribution of column humidity, and hence Earth's ability to radiate energy to space. Tobin et al. (2012, 2013) introduced a measure of convective aggregation that could be applied to satellite data to show that when convection is more aggregated the environment is on average drier, and radiates more energy to space, as hypothesized on the basis of modeling studies. Holloway et al. (2017) used 5 years of radiosonde data from Nauru, in the Pacific warm-pool region, to show that while the distribution of humidity in this region of the deep tropics is not as broad as seen in the most idealized simulations of convective self-aggregation, it is nonetheless broader than would be expected if convective self-aggregation were playing no role. Together these studies provide support for the idea that convective self-aggregation may be important for Earth's present climate, but say little about the underlying processes contributing to the aggregated state.

In models the process of self-aggregation is often studied in "moisture space." This phrase, introduced to us by A. Wing (2016, personal communication), describes the ordering of the atmospheric state by its vertically integrated (column) humidity, or moist static energy. Any circulation that arises in moisture space (i.e., as a function of rank column humidity) describes the net flow along the moisture gradient and proves to be instructive in understanding how different processes contribute to the process of convective self-aggregation. A moisture space analysis was used by Bretherton et al. (2005) to show that convective aggregation, as arises in storm-resolving simulations of radiative-convective equilibrium, is associated with a shallow circulation that is organized across moisture space so as to transport air with its moist static energy from columns with low moist static energy to columns with high moist static energy. Using a similar modeling and analysis framework Muller and Held (2012) argued that this circulation is radiatively driven, by shallow clouds forming in the dry, subsiding, air away from convection. Using a more direct manipulation of the radiative cooling, Muller and Bony (2015) further highlighted the important role a shallow circulation driven by differential radiative cooling plays in the process of self-aggregation. This is not to say that other processes are unimportant, or even insufficient, to cause convection to self-aggregate. Even without a radiatively driven shallow circulation, if aggregation inhibiting processes such as cold pools are suppressed the differential interaction of convection with dry and moist air can initiate convective selfaggregation (Jeevanjee and Romps 2013; Tompkins 2001; Craig and Mack 2013; Muller and Bony 2015). In addition a variety of diabatic processes, including surface flux anomalies and radiative effects from high clouds, contribute to the self-aggregated state, and that different processes are important for initiating, as opposed to maintaining, the self-aggregated state (Wing and Emanuel 2014; Wing et al. 2017). In the meantime, a great number of further studies have used the moisture space framework to study self-aggregation in models run in a wide variety of configurations, making this a very active area of research, with many questions still open (Jeevanjee and Romps 2013; Muller and Bony 2015; Coppin and Bony 2015; Arnold and Randall 2015; Wing and Cronin 2016; Hohenegger and Stevens 2016; Bony et al. 2016; Wing et al. 2017; Becker et al. 2017). An important gap in the literature however, is any attempt to understand the structure-and role of-various processes in the actual atmosphere using a similar framework. This study is a first attempt to begin to fill this gap.

Using 6 years of data, combined with radiative transfer calculations and reanalyses, we analyze the circulation of the atmosphere as sampled by the Barbados Cloud Observatory in moisture space. The data provide an imperfect analog to the atmosphere as studied in idealized simulations. Even to the extent they encompass a closed circulation system containing selfaggregated states, this is in the form of the seasonal migration of the intertropical convergence zone, and (at least at a first glance) quite different from what is analyzed in model simulations of RCE. Additionally, the limited scope of the measurements limits the extent to which causal inferences can be extracted from the data, and which of the ideas developed on the basis of modeling studies can be evaluated. Despite limitations imposed by working with a wild system, the moisture space representation of the data appear to encapsulate many of the features seen in the output from idealized simulations of a homogeneously forced atmosphere in radiative-convective equilibrium. In addition, the circulation as inferred from the data show evidence of a shallow component of the circulation, which is at least partially driven by differential radiative cooling of the lower atmosphere, something previous modeling studies in more idealized settings have identified as important for convective self-aggregation (Bretherton et al. 2005; Muller and Held 2012; Muller and Bony 2015; Wing et al. 2017; Naumann et al. 2017).

These points are developed in the following. The instrumentation employed and data collected for this study are presented in section 2, along with a description of auxiliary data. The suitability of the data for the present purpose is discussed in section 3 along with a presentation of the method to create a cross section in moisture space from the data. Section 4 presents this cross section and forms the basis for the analyses of the 
moist static energy transport in section 5. In section 6 we discuss the extent to which this circulation can be understood from profiles of radiative heating. The manuscript concludes with a recap of the main points, and a brief outlook in section 7 .

\section{Data}

Our analysis is centered around observations we have collected at the Barbados Cloud Observatory, whose instrumentation constitutes our primary data source. Auxiliary, or secondary data, in the form of global reanalyses of meteorological fields are also used. Both data sources are described in turn below.

\section{a. Barbados Cloud Observatory}

The Barbados Cloud Observatory (BCO) is a meteorological measurement site on a windward promontory of Barbados $\left(13^{\circ} 9^{\prime} 45.5^{\prime \prime} \mathrm{N}, 59^{\circ} 25^{\prime} 43.5^{\prime \prime} \mathrm{W}\right)$. Since its establishment - as a joint endeavor of the Max Planck Institute for Meteorology in Hamburg, Germany; the Caribbean Institute for Meteorology and Hydrology; and the Museum of Barbados-in April 2010, the BCO has been equipped with an expanding collection of state-of-the-art surface-based remote sensing instrumentation. Important for this study are its cloud radar and Raman lidar, the latter being capable of measuring water vapor. New instruments are continuously added, expanding the range of measured atmospheric properties, and contribute to make the BCO the most advanced long-term meteorological station in the broader maritime tropics. The measurements used in this manuscript are briefly described below, a fuller description and their physical context is provided by Stevens et al. (2016).

\section{1) RAMAN (WATER VAPOR) LIDAR}

A key element of this study is the water vapor profiling enabled by the Raman lidar. Several Raman systems have been built by scientists at our institute (by a team led by I. Serikov) for deployment at the BCO. These lidars are equipped with three telescopes for the close, near, and far range, each of them detecting lidar signals at the 355-, 532-, and 1064-nm wavelengths. Farand near-range telescopes are additionally equipped with water vapor channels detecting vibrational Raman return from atmospheric water vapor $(407.5 \mathrm{~nm})$ and nitrogen molecules $(387.7 \mathrm{~nm})$ stimulated at $355 \mathrm{~nm}$. The Raman system measures water vapor mixing ratio, temperature, backscatter, and extinction. Measurements of linear and volume depolarization enable the detection of a particulate shape, facilitating for instance dust detection. The lidars that have been used to date accumulate measurements at a rate of $0.1 \mathrm{~Hz}$ with a vertical resolution of $7.5 \mathrm{~m}$. These form the basis for highly resolved humidity profiles. After a validity check the humidity retrievals are performed on profiles averaged over $30 \mathrm{~min}$ in time and $60 \mathrm{~m}$ in the vertical. The retrievals provide estimates of uncertainty, and measurements with uncertainties larger than $1 \mathrm{~g} \mathrm{~kg}^{-1}$ are assigned a missing value. Such large uncertainties are caused by an increasing attenuation of the signal with height or from an optically thick cloud. In the latter case, information about the cloud vertical extent from the radar is used to correct for the saturation within the cloud [see subsection $2 \mathrm{a}(2)$ ]. Because sunlight scattered into the instrument during daytime hours greatly increase noise levels, the instrument provides less reliable, or less well-resolved, measurements during the day. For this reason our analysis is focused on nighttime measurements. An examination of dawn versus dusk differences (Fig. 1) and comparison with a differential absorption lidar system that was deployed for a shorter period of time on the BCO (Stevens et al. 2016) suggests that a focus only on nighttime data is not an important limitation of this study. Because of the subtropical location the daily cycle is changing little with season. Dusk and dawn are at similar times throughout the year and so we are able to capture meteorological comparable parts of the day.

\section{2) Cloud RADAR}

A Ka-band $(35.5 \mathrm{GHz})$ Doppler radar is used to measure cloud boundaries and, in a second step, to derive cloud fractions. Over its period of operations three cloud radars have been deployed on Barbados. Although very similar, the radars differed in their electronics, antennae, and hence beamwidth and sensitivities. For this study clouds are associated with echo boundaries greater than $-35 \mathrm{dBZ}$, and air within these boundaries is assumed saturated. This assumption may not be accurate in regions where precipitation falls through unsaturated air, but because rain events are detected less than $1 \%$ of the time series at the surface (radar reflectivity larger than $0 \mathrm{~dB} Z$ ) and unsaturated downdrafts are expected to be only a fraction of these events, their saturation depression needs to be large to take effect. Therefore biases from unsaturated precipitation shafts are assumed to be small.

The deployment of the different radars has been accompanied by periods of overlapping measurements, ensuring the intercalibration among the different systems, and present attempts to derive an absolute calibration suggest that this is within $-3 \mathrm{dBZ}$ of what is measured (Dr. L. Hirsch 2017, personal communication). Doppler spectra are processed and clouds thus 

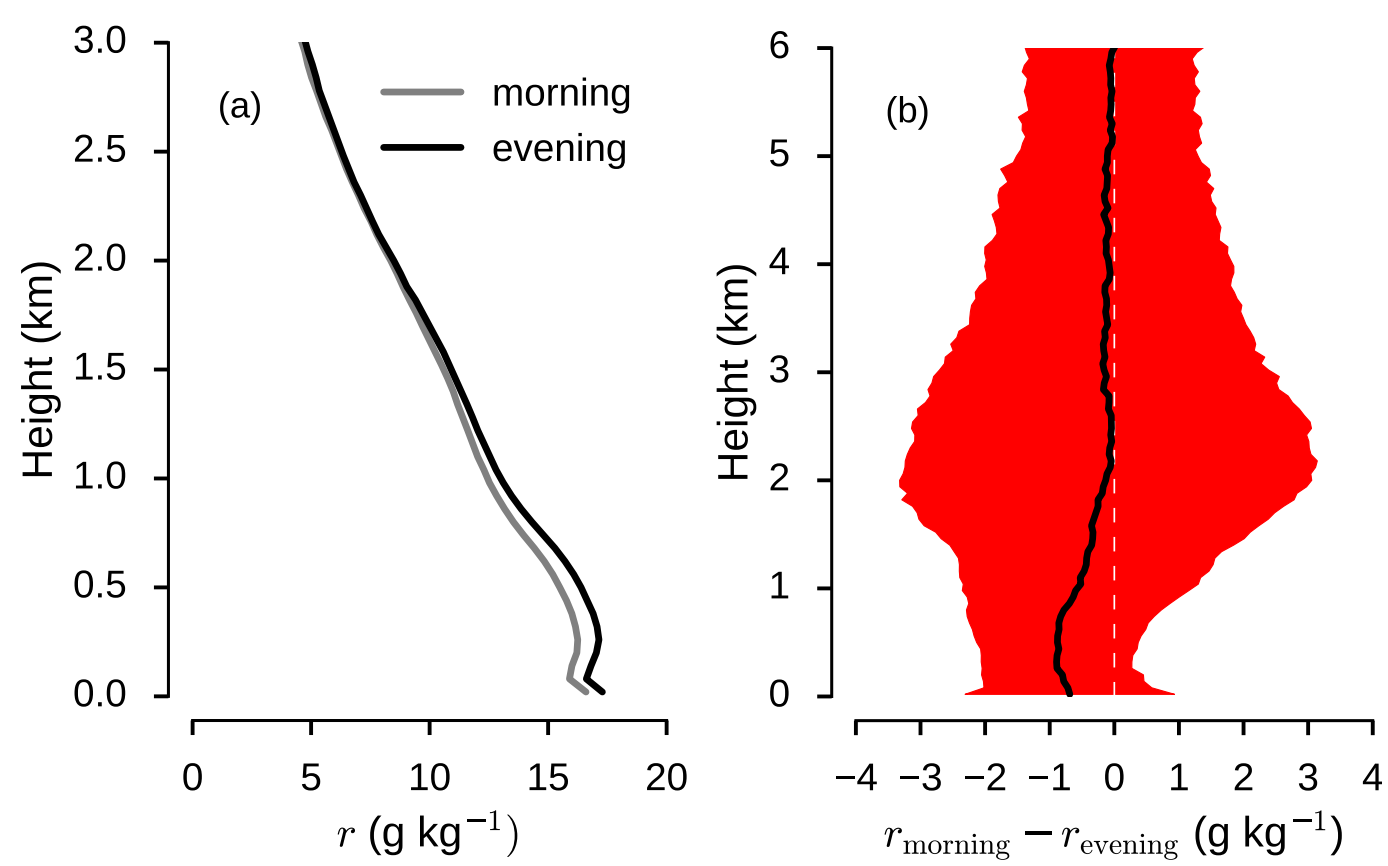

FIG. 1. Comparison of mean water vapor profiles at dusk and dawn between 2010 and 2016. (a) Mean profiles of mixing ratio $r$ for dusk and dawn and (b) difference between dusk and dawn moisture profile with mean (black) and standard deviation (red).

marked with a temporal resolution of $10 \mathrm{~s}$ over $30-\mathrm{m}$ range bins. Although the cloud radars can detect signals well below $-50 \mathrm{~dB} Z$ at cloud base, a rather higher cloud threshold was chosen to enable cloud detection in the upper troposphere, where sensitivities are lower, and to minimize the mischaracterization of drizzle falling through subsaturated air as being cloud. Apart from increasing the apparent cloud fraction everywhere, sensitivity tests using a lower threshold, $-45 \mathrm{~dB} Z$, did not appreciably change the result. Cloud entities and cloud-base height measured by the radar are used to calculate in-cloud humidity by moist adiabatically raising the water vapor mixing ratio detected by the lidar at the cloud base to the cloud top.

\section{3) RADIOSONDES}

To complete humidity and temperature profiles even above clouds or in heights where the backscatter signal can be too weak to be within the limits of the allowed statistical uncertainty, radiosonde measurements of temperature and relative humidity are used. Some originate from the site itself, but most are launched at the local airport at $0000,0600,1200$, or 1800 UTC, with the 1200 UTC launch time being most common. The airport sounding site is located about $12 \mathrm{~km}$ south-southwest of the $\mathrm{BCO}$ at a slightly more inland location on the south coast (Stevens et al. 2016). By comparing sondes during their ascent, and descent, or with dropsondes launched by aircraft offshore a slight island effect can be discerned in the lower few kilometers (Dr. J. Kiliani 2016, personal communication), but within the boundary layer the data quality of the lidar is sufficient so that radiosonde profiles are required to fill in the time series less than $1 \%$ of the time.

\section{b. Reanalysis}

Five different reanalyses provide supplementary large-scale vertical velocities from maritime domains east of Barbados. In particular, ERA-Interim, JRA-55, NCEP-DOE, MERRA, and the first 7-yr segment of the fifth generation of the ECMWF atmospheric reanalyses (ERA5) are used. ERA5 has 137 hybrid sigma-pressure (model) levels (Hersbach and Dee 2016) and the highest vertical resolution of the vertical velocity field within this study, followed by MERRA with 42 pressure levels (Rienecker et al. 2011) and ERA-Interim (Dee et al. 2011) and the Japanese reanalysis (JRA-55) based on the Japan meteorological system as of December 2009 (Kobayashi et al. 2015; Japan Meteorological Agency 2013) with each having 37 pressure levels. The coarsest resolution among the used reanalyses is the vertical velocity product of the NCEP-DOE reanalysis with only 12 pressure levels below $100 \mathrm{hPa}$ (Kanamitsu et al. 2002). Because we only use humidity measurements during the night we make use of the reanalysis products valid at 0000 UTC (2000 local time), which 
should sufficiently reflect the average large-scale vertical motion.

\section{Constructing the moisture space representation of the atmosphere over the BCO}

Studying processes of convective self-aggregation in moisture space is intuitive, in that convective selfaggregation is accompanied with an increased differentiation of integrated water vapor (IWV) between dry and moist regions. The idea of constructing a moisture space cross section from measurements made in time from a single point is, however, less intuitive. Tacit is the idea that the states measured over time at the single point in space adequately sample the different moisture states of the tropical atmosphere. This line of thinking is encouraged by virtue of Barbados sitting at the edge of the ITCZ, where (according to the reanalyses) the mean midtroposphere $(500 \mathrm{hPa})$ vertical velocity is (when averaged over the year) near zero (Stevens et al. 2016). The seasonal migration of the ITCZ is responsible for this situation, as it allows the BCO to sample both the winter trades that fuel the ITCZ and convection within the ITCZ. The assumption made in this analysis is that the convection from the ITCZ - as mostly sampled in the wet season over Barbados-is characteristic of the convection in the ITCZ that lies equatorward of the $\mathrm{BCO}$ in its dry season and matches to the then sampled subsiding motion.

The basic ingredients of the moisture space representation of the atmosphere over the $\mathrm{BCO}$ are derived from humidity profiles measured by the Raman lidar measurements, cloud masks provided by the radar, and measurements with radiosondes to fill data gaps. Missing values can arise for various reasons, for instance, due to a large statistical uncertainty of the measurement (recall that uncertainties of $1 \mathrm{~g} \mathrm{~kg}^{-1}$ are treated as unreliable and masked). In the presence of missing values, chronologically close lidar profiles are considered as a first option. In higher altitudes, however, this approach has a limited effect as the lidar signal's statistical uncertainty is too large. In these cases, the missing data are filled by radiosondes launched daily at the nearby Grantley Adams airport. In the infrequent case that there has been no launch within a 12-h interval around the time of the missing value, a climatology value originating from 6 years of soundings is used. The usage can be as high as $10 \%$ close to the tropopause, but drops down to less than $1 \%$ within the lower $6 \mathrm{~km}$.

If, however, a missing value lies in a range gate that has been detected to be cloudy by the radar, special care needs to be taken as inside a cloud the humidity can differ substantially from its surrounding area and needs to be accounted for. To do so, we isentropically raise an air parcel with thermodynamic properties retrieved at the cloud base to the radar-detected cloud top. The saturation humidity within the air parcel is taken as an approximation of the humidity within the cloud. This procedure, however, requires knowledge of the cloud-base temperature. Similar to the routine for finding water vapor measurements, collocated temperature information is retrieved from radiosondes and its climatology.

All humidity profiles are constrained to physical boundaries implied by saturation. Humidities that are supersaturated when compared to saturation values inferred from ERA-Interim temperature profiles are set to saturation.

Figure 1a compares humidity profiles from dusk and dawn and reveals that a slightly moister boundary layer exists in the evening (2130-2230 UTC, or 1730-1830 local time) than in the morning (0830-0930 UTC). This difference is about $1 \mathrm{~g} \mathrm{~kg}^{-1}$ and vanishes on average at an elevation of $2 \mathrm{~km}$ as seen in Fig. 1b. To exclude the possibility of being sensitive to this diurnal cycle rather than to the large-scale processes, we created nightly averages (1930-0730 local time) of the humidity profiles for the following analyses.

To rank the averaged profiles by IWV, the water vapor specific humidity $q$ in each range gate is weighted by the ambient air density $\rho$ and then integrated over the atmospheric column:

$$
\begin{aligned}
\mathrm{IWV} & =\int_{0}^{z_{t}} \rho q d z, \quad \text { where } \\
\rho & =\frac{p}{R_{d}\left[1+\left(\frac{R_{v}}{R_{d}}-1\right) q\right] T} .
\end{aligned}
$$

Here $p$ denotes pressure; $T$ is temperature; and $R_{v}$ and $R_{d}$ are the specific gas constants of water vapor and dry air, respectively. The integration limits are from the surface to the top of the troposphere. In deriving this expression it is assumed that the mass loading of condensate has a negligible effect on the effective gas constant. In addition, for simplicity, fixed temperature and pressure profiles are assumed for $p$ and $T$. Throughout the year, temperature deviates in the troposphere by $3^{\circ} \mathrm{C}$ (10th-90th percentiles) from the mean, but these deviations only affect the dry air density as the humidity is measured in an absolute manner. Uncertainties that arise because of this simplification are less than $1 \%$ in terms of the integrated water vapor (not shown). In the later discussion we introduce the vertical averaging operator, so that for an arbitrary variable $\chi$, 

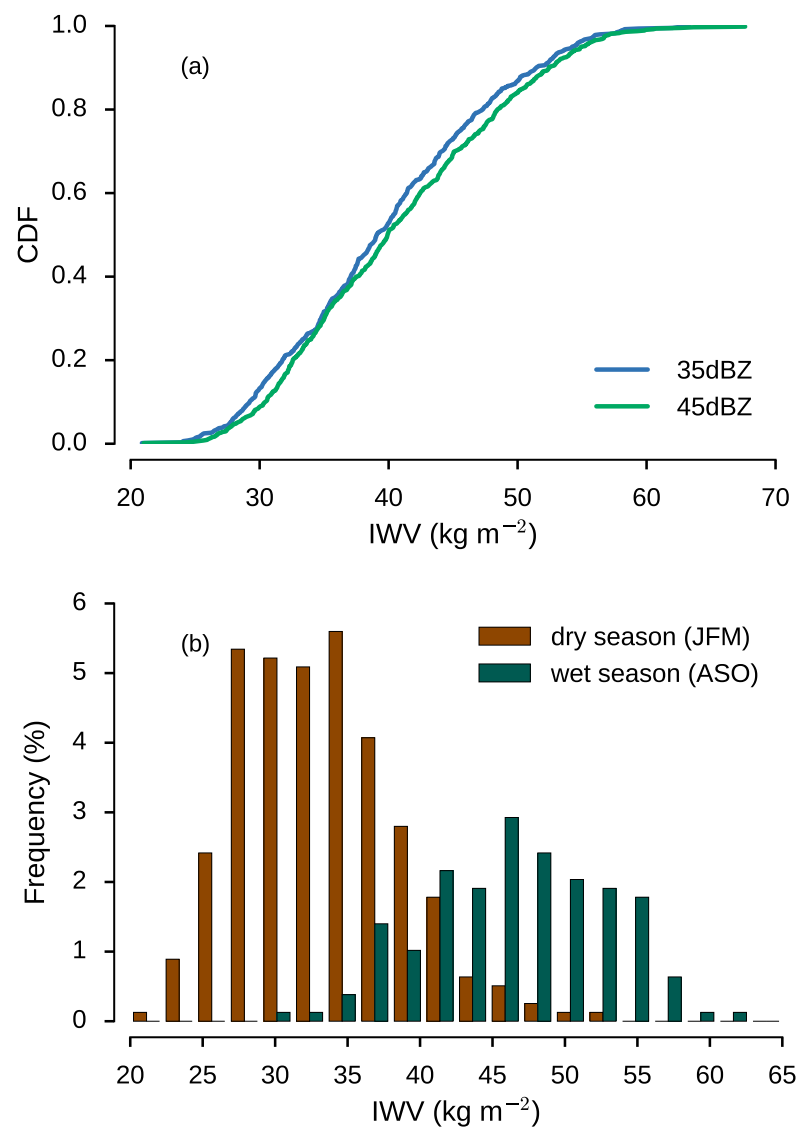

FIG. 2. Integrated water vapor (IWV) statistics from the BCO profiles: (a) cumulative distribution function of IWV for a -35 - and a $-45-\mathrm{dB} Z$ cloud-mask threshold; (b) seasonal distribution of IWV measured at the BCO (2010-16) with a cloud mask based on $-35-\mathrm{dB} Z$ reflectivity threshold.

$$
\langle\chi\rangle \equiv \frac{1}{p_{s}-p_{t}} \int_{p_{t}}^{p_{s}} \chi d p
$$

where $p_{s}$ and $p_{t}$ denote the pressure at the surface and tropopause respectively. In terms of this notation it follows that IWV $=\left(p_{s}-p_{t}\right) g^{-1}\langle q\rangle$, with $g$ being Earth's gravitational acceleration.

IWV values range from about 20 to over $60 \mathrm{~kg} \mathrm{~m}^{-2}$. The distribution of values is illustrated by the cumulative distribution function (Fig. 2a), which places the 10th percentile of the distribution at $30.3 \mathrm{~kg} \mathrm{~m}^{-2}$ and the 90th percentile at $48.1 \mathrm{~kg} \mathrm{~m}^{-2}$. The exact threshold chosen for the cloud masking, which affects the assumed saturated area of the atmosphere, does not substantially influence the cumulative distribution function of IWV (Fig. 2a). In the tropics, with convection forming over sea surface temperatures near $300 \mathrm{~K}$ an IWV of about $60 \mathrm{~kg} \mathrm{~m}^{-2}$ represents an atmosphere that is saturated above a shallow cloud base. For a completely dry free atmosphere topping a 600-m-deep marine boundary layer,

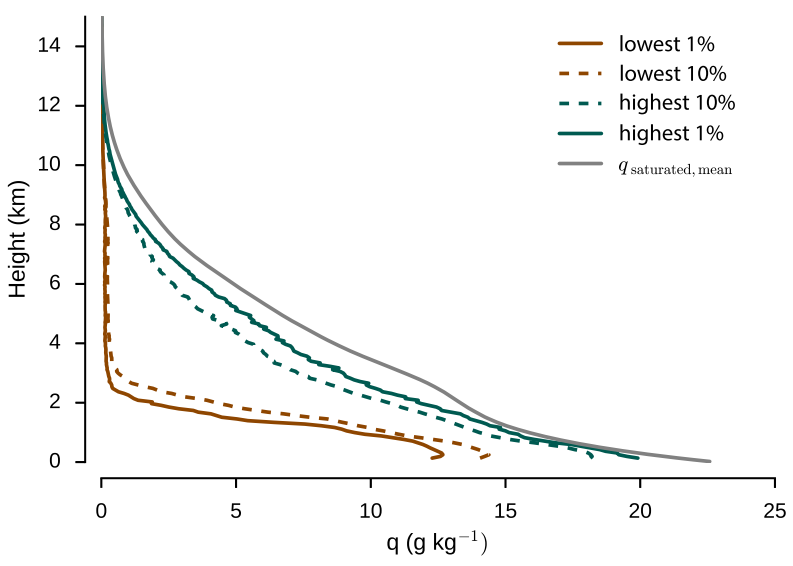

FIG. 3. Mean water vapor mixing ratio profiles for the highest and lowest percentages of ranked IWV.

with a specific humidity of $17 \mathrm{~g} \mathrm{~kg}^{-1}$, the IWV is about $12 \mathrm{~kg} \mathrm{~m}^{-2}$. Hence, we conclude that the BCO relatively well samples a wide range of IWV.

A clear distinction is evident in the distribution of IWV between the dry [January-March (JFM)] season and the wet [August-October (ASO)] season. This is illustrated by Fig. $2 b$, which also shows that the wet season makes no contribution to the lower decile of IWV, likewise in the dry season there is also relatively little contribution to the upper IWV decile. These differences between the wet and dry season are similar to what is sampled by aircraft dropsondes during the Next Generation Aircraft Remote Sensing for Validation Studies (NARVAL) field campaigns (Stevens et al. 2017) over a much larger area, but smaller period of time. In particular, the profiles highlight a characteristic feature of the dry season, which is the presence of a welldefined marine layer capped by a very dry atmosphere above $2 \mathrm{~km}$. This characteristic is also evident in the observed profiles of the specific humidity as sampled over the driest versus the moistest periods (e.g., Fig. 3). Despite some overlap, the fact that the wet and dry season IWV histograms are clearly distinct, emphasize how-in our analysis - temporal variability of the ITCZ is correlated with variability in IWV. In effect our analysis uses temporal variability to sample spatial variability, a fact that must be borne in mind when interpreting our findings.

The full BCO moisture space cross section of specific humidity and cloudiness, ordered by IWV, is shown in Fig. 4a. The figure is redolent of similar cross sections created using storm-resolving simulations of RCE in the presence of convective self-aggregation. Cloudiness does not vary simply with IWV. The maximum in lowlevel cloudiness-with cloud amounts commensurate to the maximum cloudiness at any point in moisture 

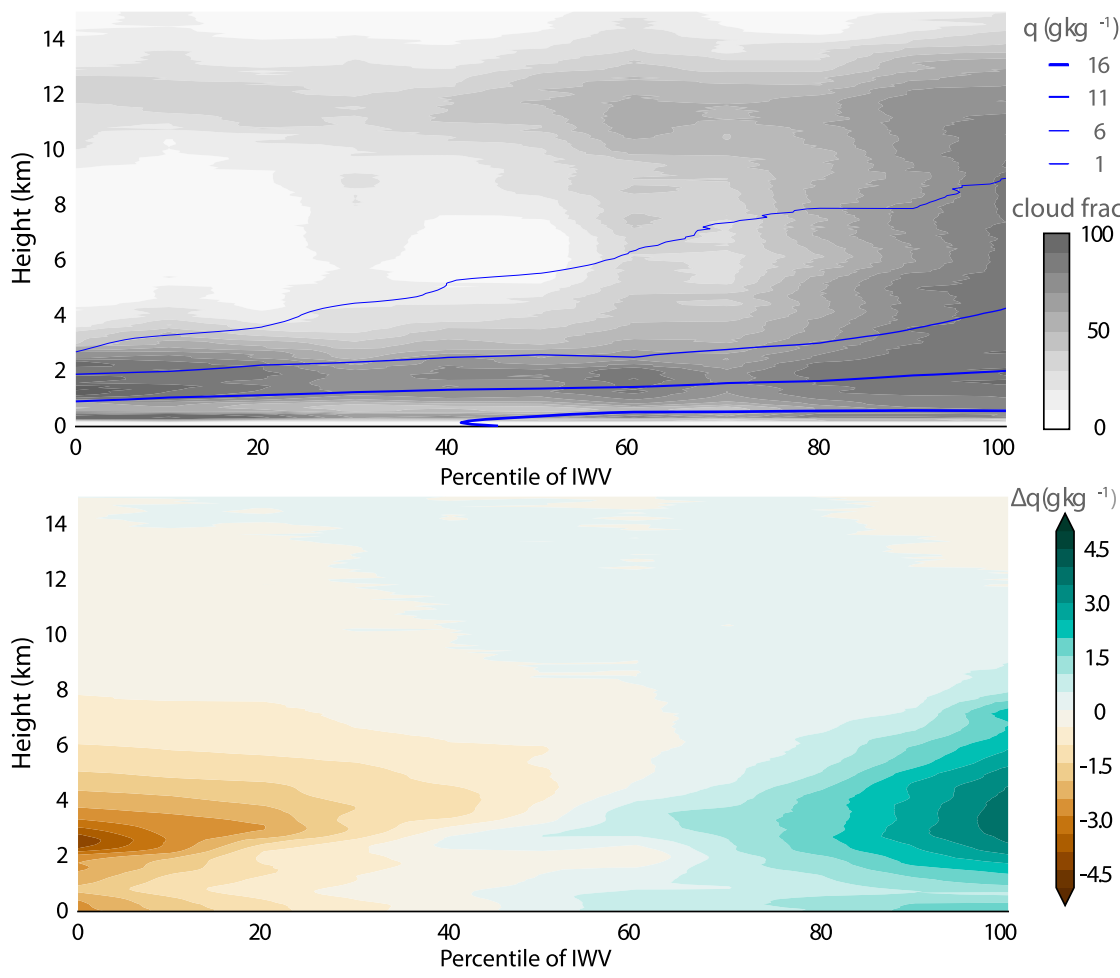

FIG. 4. Observational cross section in moisture space sorted from the driest column on the left to the moistest one on the right. (a) Low-level cloud amount (shades of gray) varies little across the moisture space, while the specific humidity (blue contours) increases, (b) especially at heights between 2 and $4 \mathrm{~km}$.

space-is actually found in the driest atmospheres, at a height of around $1.5-2.0 \mathrm{~km}$. Differences in the humidity are most pronounced above this layer, at heights between 2 and $4 \mathrm{~km}$. As in the simulations, the observed clouds reach deeper and span the troposphere as IWV increases, with cloudiness through the middle troposphere increasing coherently and sharply in the upper quintile of the IWV distribution. High clouds are evident over the BCO even in the driest conditions, their presence may be indicative of the fact that the IWV is relatively insensitive to values of humidity in the upper troposphere-in fact, at $14 \mathrm{~km}$, specific humidities are actually lower in the moistest columns (Fig. 4b). There are also some differences between the moisture space representation of the observations and those of simulations in RCE. For instance, in the planetary boundary layer (roughly the lower $500 \mathrm{~m}$ ) differences in humidity, though modest are influenced by dry-season sea surface temperatures being somewhat lower than those during the wet season. The variability of surface temperature across moisture space, and its effects, is not present in the most idealized simulations, for which sea surface temperatures are held fixed. RCE simulations with interactive SSTs, such as are performed using storm-resolving, but also climate, models (Hohenegger and Stevens 2016; Coppin and Bony 2017), do account for these differences and show similar features, albeit less pronounced as the insolation is homogenized across the domain in the simulations but not in the observations. Notwithstanding these differences, the main features and similarities of the moisture space representation of the observations vis-à-vis the simulations are quite robust to the details of how the moisture space cross section is constructed. We have also constructed a similar figure using a different cloud threshold $(-45 \mathrm{dBZ})$, and by ranking humidity by contributions to the IWV above $3 \mathrm{~km}$, or by using moist static energy, rather than IWV, as the order parameter. None of these changes has an appreciable effect on the main features of the cross section as outlined above.

The separation in moisture space in Fig. 4 is similar to what one finds with convective self-aggregation at correspondingly warm sea surface temperatures (e.g., Holloway and Woolnough 2016). In our case, however, the degree of convective organization it implies is partially forced, as it is associated with the large-scale overturning circulation in the form of the Atlantic ITCZ. The moist areas are predominantly from the wet 
season when easterly waves and convection within the ITCZ reaches northward over the $\mathrm{BCO}$, and the very dry profiles come from the dry season, which is typified by the winter trades, with the ITCZ and deep convection well equatorward of the BCO. Although constructed from point measurements collected over time, it may just as well correspond to a cross section through the ITCZ. Hence, features such as the minimum in lowertroposphere cloudiness near the median values of the IWV may be indicative of the lower troposphere being less cloudy during suppressed conditions during the wet season, as for instance shown by Nuijens et al. (2014).

\section{Circulation in moisture space}

Circulations in moisture space can be nonintuitive. In a closed, or periodic, domain their interpretation is actually quite simple, as streamlines in moisture space describe the mean flow along (i.e., in the same direction as) the moisture gradient. Even so, because the mean flow in physical space is not necessarily along the moisture gradient, many find these circulations rather unintuitive. In an open domain, such as we consider, these difficulties are compounded. Over the BCO we do have the advantage that, as we shall see, the mass budget is approximately closed. However, because this constraint only guarantees that the same amount of mass enters the domain as leaves it, it does not guarantee that the topology of the mean flow along the moisture gradient is the same in moisture and physical space. However, given the sense of the flow along a cross section terminating with ascent into the ITCZ, we believe that the circulation in moisture space, as defined by our measurements, can be informative as to the role of various processes in determining the distribution of IWV.

As a check of the closure of the mass budget, in Fig. 5, the seasonal-mean pressure velocity at $500 \mathrm{hPa} \omega_{500}$ is plotted for different reanalysis products. In case of the ERA-Interim and the JRA-55 from 1979 to $2015, \omega_{500}$ is only marginally positive, adopting values of 0.5 and $1.5 \mathrm{hPa} \mathrm{day}^{-1}$, respectively. The NCEP reanalysis, suggests a larger value $\left(6 \mathrm{hPa} \mathrm{day}^{-1}\right)$, whereas MERRA places the $\mathrm{BCO}$ in a region with, on average, mean rising motion $\left(\omega_{500}=-3.6 \mathrm{hPa}\right)$. Comparable data from ERA5 are not available yet. Nonetheless, considering that the monthly mean value of $\omega_{500}$ can be more than $\pm 30 \mathrm{hPa} \mathrm{day}^{-1}$, all but the older NCEP reanalysis suggest that the mass budget over the BCO is relatively closed. In practice, however, gaps in the data coverage (resulting from instrument down time) over the 6-yr-long time series do not randomly sample the annual cycle. Hence, sampling $\omega_{500}$ over only those days where we

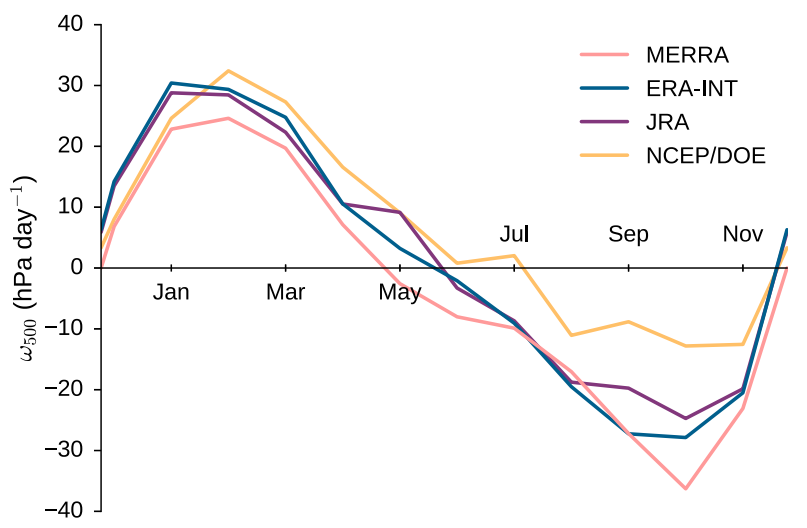

FIG. 5. Monthly climatology of midtropospheric vertical pressure velocity $\omega_{500}$ over Barbados region as represented by several reanalyses (1979-2015).

have measurements leads to a mass budget that is somewhat less balanced than the climatological mean, which would imply some mass divergence, or leakage, of the circulation in the moisture space defined by our observations.

Even if no net mass entered or left the observed system, it would not imply that the system was closed, as the mass entering the system need not be the same as the mass leaving the system. For example, low-level air masses and high-level air masses are not necessarily connected locally in nature, so low-level inflow that we sample may originate from upper-level outflow elsewhere, so that our analysis implicitly assumes that this has similar characteristics as the outflow we do sample. If this assumption is reasonable anywhere, it will be valid in the tropics, as temperature gradients in the free troposphere are small and a fair amount of the overturning circulation is confined to the tropical belt (Pauluis et al. 2010). To construct the circulation in moisture space at the $\mathrm{BCO}$ we composite the reanalysis vertical velocity profiles over the dates contributing to a particular rank of the IWV. Thus in each bin, or rank, of IWV we can construct a mean vertical velocity profile. Then, similar to the method described by Bretherton et al. (2005) the streamfunction $\Psi$ is given as a function of the pressure by

$$
\Psi_{i}(p)=\Psi_{i-1}(p)+\frac{\omega_{i}(p)}{g} \alpha,
$$

where $i$ is the rank in moisture space, and $\omega_{i}$ is the mean profile of vertical pressure velocities within rank $i$. To be independent of the bin size, a weight $\alpha$ is applied such that $\alpha N_{\text {bins }}=1$. In the driest column of a closed system the mean flow along the moisture gradient can, by definition, only exchange mass with moister columns. Likewise the moistest columns can only exchange mass 

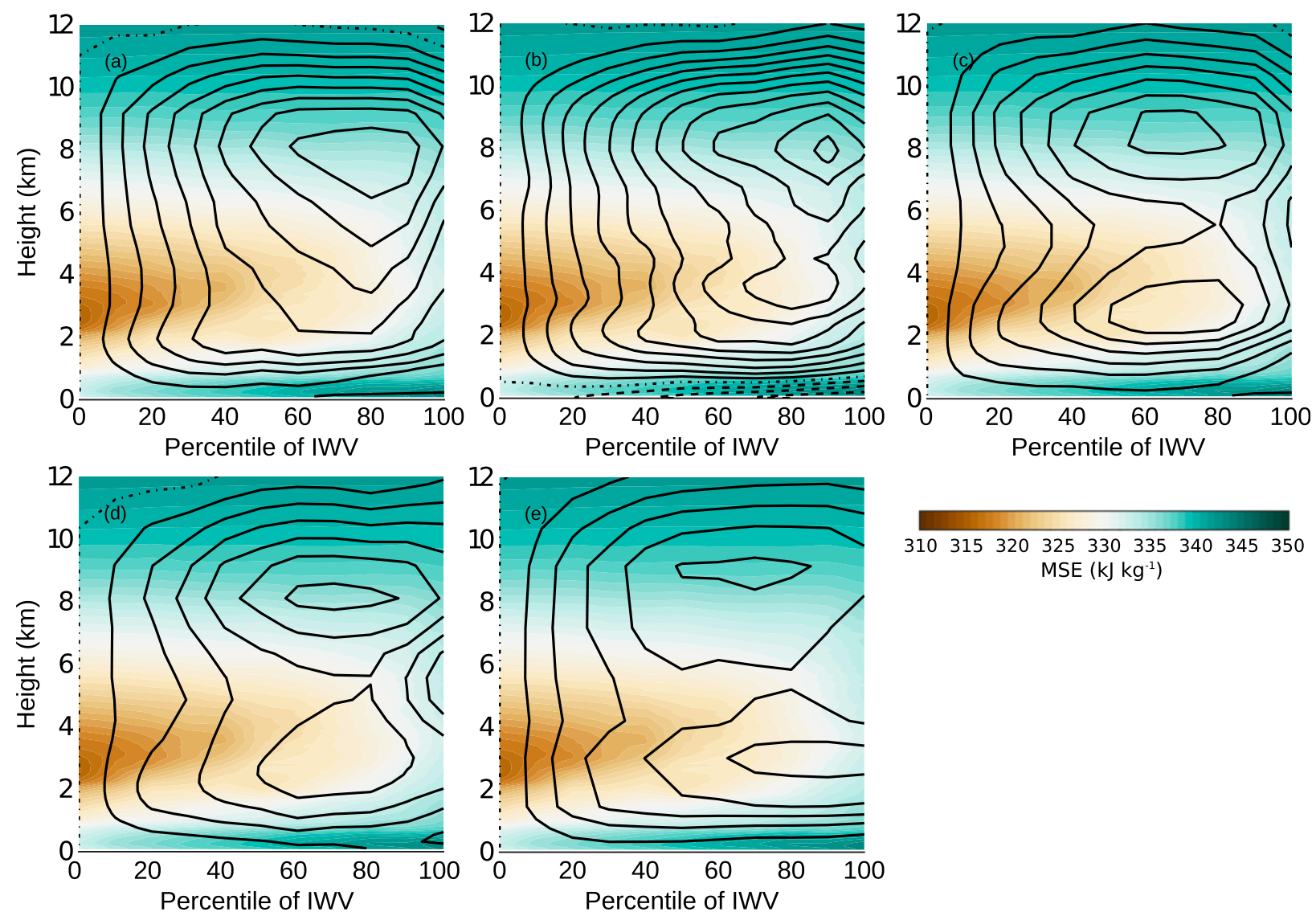

FIG. 6. Circulation in observational moisture space extracted from reanalysis: (a) ERA-Interim, (b) ERA5, (c) JRA, (d) MERRA, and (e) NCEP-DOE. Black contours represent streamfunction $\Psi$ (contours interval $=0.4 \mathrm{~g} \mathrm{~m}^{-2} \mathrm{~s}^{-1}$ starting at $0 \mathrm{~kg} \mathrm{~m}^{-2} \mathrm{~s}^{-1}$; dashed if negative). Color shading corresponds to moist static energy.

with drier columns. This provides the boundary conditions for estimating the streamfunction, $\Psi$ in Eq. (3). In an open system we need to either assume that we sample the moistest, or driest column, so that this condition is still true. We assume here, that the driest atmospheric columns are captured by the observations, so that there can be no exchange of mass with yet drier columns. A lack of closure in the mass budget then shows up (by construction) in the form of open streamlines at the moist end of the moisture space. A different approach would be to simply subtract the mean $\omega$ at each level, so as to construct the anomalous circulation streamfunction $\Psi^{\prime}$. The method we adopt, while it cannot distinguish to what extent the lack of closure is more on the dry or moist end of moisture space, at least gives an indication or measure of its degree of closure.

Despite these difficulties, and despite substantial differences in the vertical velocities provided by the reanalyses, the mean circulation in moisture space arising from the different reanalyses (Fig. 6) appears physically plausible and shares many common features.
Irrespective of the reanalysis used, a large overturning circulation with rising to the tropopause in the moist region, and sinking in the dry region of moisture space emerges. The circulation is top heavy, maximizing in strength at about $8-9 \mathrm{~km}$. To differing degrees all reanalysis products also show what we interpret to be a shallow circulation superimposed on the deep circulation. This is evident either as a secondary maximum in four of the reanalyses, or in the form of a plateau in the case of the ERA-Interim (Fig. 6a). Its successor, ERA5, shows the secondary maximum as well instead of the plateau. In each case this feature locates near the 70th percentile of the IWV distribution, and at a height of about $2.5 \mathrm{~km}$, near a minimum in the vertical profile of moist static energy.

This interpretation of the circulation as being composed of two pieces, a deep top-heavy circulation and an embedded shallower circulation, follows from the expectation that convective heating is top heavy and left to its own devices would drive a deep circulation. A top-heavy convective heating profile is thought to 


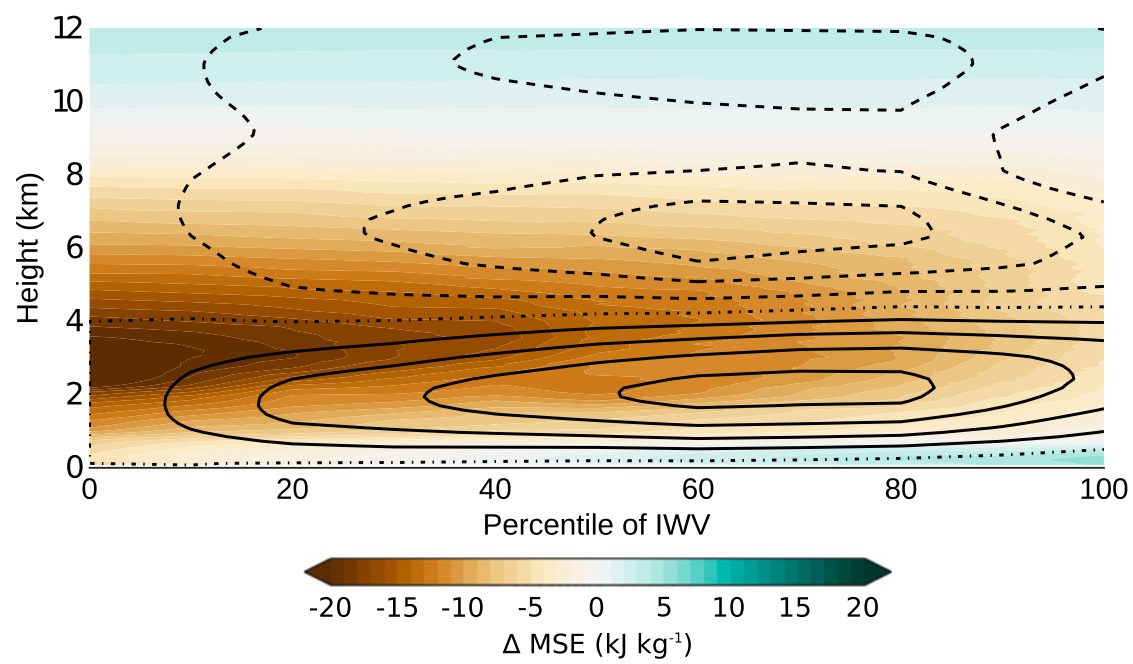

FIG. 7. Shallow circulation constructed as the residual from the composite ERA5, MERRA, and JRA. Black contours represent streamfunction $\Psi$ with the same contour interval as in Fig. 6. The maximum of the low-level streamfunction is $1.5 \mathrm{~g} \mathrm{~m}^{-2} \mathrm{~s}^{-1}$. Color shading depicts the MSE anomaly relative to the mean surface MSE.

arise because stratiform precipitation processes in regions of deep convection tend to be associated with condensational heating above the freezing level, and evaporative cooling at lower levels, and because of the radiative effects of stratiform precipitation features (Houze 1982). Thus, the secondary maximum, or lowertroposphere amplified circulation, is surprising, but similar to what is seen in the studies of radiative-convective equilibrium (Bretherton et al. 2005). In such simulations, this shallow circulation emerges in a way that supports and organizes the deep convection, but is not driven by the deep convection itself, rather by radiative perturbations that accompany the distribution of clouds and water vapor in the lower troposphere.

To better isolate the role of this anomalously shallow contribution to the circulation we assume a large-scale (top heavy) circulation, and define the shallow circulation as the residual between the total circulation and the best-fit deep circulation. Similar to Fläschner (2016), we assume a top-heavy large-scale vertical velocity of the form, $\omega_{\mathrm{ls}}=\langle\omega\rangle \Omega(p)$ where the shape profile $\Omega(p)$ is beta distributed as

$$
\begin{array}{r}
\Omega(p)=\frac{\left(p-p_{t}\right)^{a-1}\left(p_{s}-p\right)^{b-1}\left(p_{s}-p_{t}\right)^{-a-b+2}}{B(a, b)} \\
\text { for } p_{s} \geq p \geq p_{t} .
\end{array}
$$

The shape parameters, $a$ and $b$ are chosen such that a top-heavy profile accrues, which coincides with the mean profile of each reanalysis, and $B$ denotes the beta function. Because the beta distribution has compact support, $\Omega(p)$ vanishes for $p \notin\left\{p_{s}, p_{t}\right\}$. In every case, we take $p_{s}=1000 \mathrm{hPa}$, whereas $p_{t}$ is determined separately for each reanalysis as the height above $200 \mathrm{hPa}$ where the mean vertical velocity changes sign. With this setup, the maximum of the vertical velocity profile lies in the upper troposphere and resembles a typical tropical vertical velocity profile.

Following the above procedure we are able to recreate the implied shallow component to the total circulation for each of the reanalysis products. Because they do not end up differing substantially, in Fig. 7 we present the shallow circulation from the average of the three most modern (and vertically best resolved) reanalyses (ERA5, JRA, MERRA). The exact shape of the shallow circulation depends on the assumed shape of the deep circulation; however, the features of the shallow circulation are relatively insensitive to the chosen reanalysis, or to small changes in how one constructs the deep circulation. All show that the assumption of a top-heavy convective heating profile implies the existence of a shallow circulation. In each case the shallow circulation is in the sense of the deep circulation, but concentrated below the triple-point isotherm at around $4.5 \mathrm{~km}$, with the strongest flow near the surface (from regions of low IWV to regions of high IWV) and in a "return flow" layer near $3 \mathrm{~km}$. This shallow circulation is similar to radiatively driven shallow circulations seen in the process of aggregation for simulations of radiativeconvective equilibrium. To better visualize the MSE transport, the anomaly of MSE relative to the mean surface MSE is shown. In the next section, we consider 
the evidence for it playing a similar role in our observations of the circulation surrounding the seasonal migration of the ITCZ.

\section{Moist static energy transport}

The effects of the circulation in moisture space can be interpreted with the help of the budget of moist static energy (e.g., Raymond et al. 2009), which we denote by $h$. To a reasonable degree of approximation only diabatic processes affect large-scale (or ensemble averaged) values of $h$, so that its time evolution can be described as follows:

$$
\frac{\partial \bar{h}}{\partial t}+\overline{\mathbf{v}} \cdot \nabla \bar{h}=-\nabla \cdot \overline{\mathbf{v}^{\prime} h^{\prime}}+g \partial_{p} \bar{F}_{r},
$$

where the overline (:) denotes an ensemble average (where the ensemble is meant in the sense of many realizations of a flow), and the prime $\left(.^{\prime}\right)$ denotes deviations from this mean. The flow is denoted by the vector velocity $\mathbf{v}=\{\mathbf{u}, \omega\}$. The term $\bar{F}_{r}$ denotes the net (upward) irradiance. Integrating Eq. (5) over the vertical yields the budget for vertically integrated moist static energy:

$$
\frac{\partial\langle\bar{h}\rangle}{\partial t}+\left\langle\overline{\mathbf{u}} \cdot \nabla_{h} \bar{h}\right\rangle+\left\langle\bar{\omega} \partial_{p} \bar{h}\right\rangle=\bar{F}_{h}\left(p_{s}\right)-\left[\bar{F}_{r}\left(p_{t}\right)-\bar{F}_{r}\left(p_{s}\right)\right] .
$$

In deriving Eq. (6) horizontal eddy fluxes of $h$ are assumed negligible, so that all that remains from the rhs of Eq. (5) after the vertical integral is the surface flux contribution; that is, the vertical eddy flux at the surface $\bar{F}_{h}$ and the difference between the irradiance at the top of the atmosphere and the surface.

In idealized simulations of radiative-convective equilibrium the emergence of a shallow circulation driven by differential radiative cooling is interesting because it tends to enhance the moisture variance, and thus supports convective self-aggregation (e.g., Bretherton et al. 2005; Wing et al. 2017). One apparent exception to this rule is reported by Jeevanjee and Romps (2013) who, on the basis of two-dimensional simulations in the aggregated state, found that the shallow circulation acts to reduce the variance in integrated water vapor, increasingly so for smaller domains. The more typical effect of a shallow circulation, particularly in the aggregating phase, is to act to increase moisture variance, which it does by exporting (along its upper branch) low moist static energy $h$ from regions where $h$ is high to regions where $h$ is low and importing (through its lower branch) high moist static energy from regions where it is low to regions where it is high: the rich get richer and the poor get poorer.

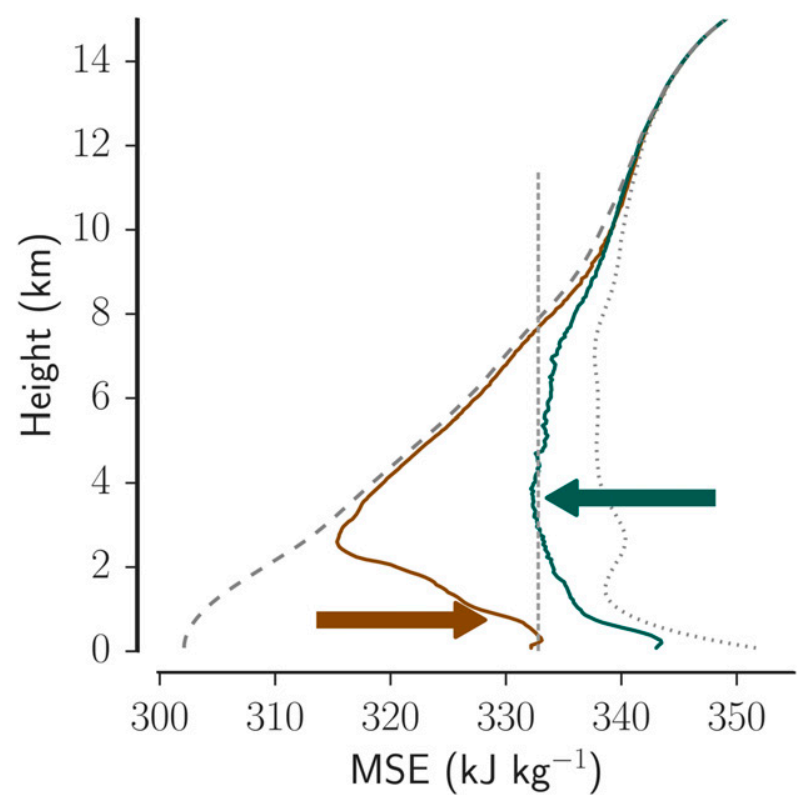

FIG. 8. Moist static energy profiles of the driest (brown) and moistest (blue-green) decile. The mean flow of the shallow circulation (arrows) imports and exports similar moist static energies (gray vertical line). The relative position of the moist static energy profile between the dry static energy profile (dashed) and the saturated moist static energy (dotted) indicates the relative humidity.

In our analysis of the large-scale circulation associated with the Atlantic ITCZ-as observed over the BCOthe presence of a shallow circulation appears to play a similar role. This becomes apparent upon analysis of the moist static energy transport by this circulation, something that can be ascertained graphically because in the absence of diabatic processes the moist static energy is invariant following the flow. Figure 8 compares a moist static energy profile from the lower decile of the IWV distribution, where $\langle h\rangle$ is small, to the upper decile of the IWV, where $\langle h\rangle$ is large. The largest difference between $\bar{h}$ in the small and large $\langle h\rangle$ regions is found at about $3 \mathrm{~km}$, above about $9 \mathrm{~km} h$ is similar between the two regions. More importantly, $\bar{h}$ at $3 \mathrm{~km}$ in the moist columns is similar to its near-surface value in the dry columns. We interpret this near equality in the value of $\bar{h}$ along the importing and exporting branch of the shallow circulation as indicative of the role of the shallow circulation in supporting the observed state of aggregation/ moisture variability. As the moister regions approach saturation such a circulation would become progressively less effective in sustaining the observed structure and even act to reduce the variance in IWV (or column moist static energy) if the moist columns moisten sufficiently in the lower free troposphere. So although an important role for other processes-such as surface fluxes, which the data do not allow us to readily quantify—cannot be 
ruled out, the measurements are in line with what one would expect if shallow circulations driven by differential radiative cooling played an important role in determining the state of aggregation.

This is a simplistic view on the transport of MSE, and, as we shall see, the shallow circulation in our observations is still intensifying the moisture variance if we not only concentrate on the extreme deciles, but on the complete transect. Diabatic processes that accompany the shallow circulation further amplify the increase in variance associated with the shallow circulation. Surface moisture fluxes increase the $\bar{h}$ in the planetary boundary layer as air advects to regions where $\langle h\rangle$ is large, and radiative processes are a sink of $\bar{h}$ as air advects out of the moist regions (large $\langle h\rangle$ ) and returns to the dry region. This is in contrast to a deep circulation. At $12 \mathrm{~km} \bar{h}$ in the moist column is $10 \mathrm{~kJ} \mathrm{~kg}^{-1}$ higher than the nearsurface $\bar{h}$ in the dry column, emphasizing the export of energy out of the column, and the importance of surface and radiative fluxes for maintaining the observed variance in column moist static energy.

To look at these issues more precisely, we explore the adiabatic component of the budget for $\langle\bar{h}\rangle$ in more detail. This implies a quantification of how the advective terms contribute to the budget, that is,

$$
\frac{\partial\langle\bar{h}\rangle}{\partial t}=-\left\langle\overline{\mathbf{u}} \cdot \nabla_{h} \bar{h}\right\rangle-\left\langle\bar{\omega} \partial_{p} \bar{h}\right\rangle+Q
$$

where $Q$ represents the diabatic terms [e.g., in the rhs of Eq. (5)]. Often this budget is simplified by neglecting the horizontal component to the advective budget, and focusing on how a single deep mode of the vertical velocity, such that $\bar{\omega}=\langle\omega\rangle \Omega(p)$, defines an effective relationship between the forcings and the "gross moist stability" defined as $\Gamma_{m}=\left\langle\Omega \partial_{p} \bar{h}\right\rangle$, in which case the stationary form of Eq. (6) reduces to the simple balance $\langle\omega\rangle=-Q / \Gamma_{m}$ (Neelin and Held 1987; Raymond et al. 2009). The presence of a shallow circulation calls the ansatz of parameterizing vertical motion into single deep vertical mode into question. Similarly, Back and Bretherton (2006), and other studies have questioned the validity of neglecting the horizontal advection terms (Raymond et al. 2009). For this reason we quantify contributions to both the vertical and horizontal advective terms, from the total circulation in moisture space and from the diagnosed shallow component.

The vertical structure of the advective tendencies of $\bar{h}$ are presented in Fig. 9, for both the total and (diagnosed) shallow circulation. Their vertical integrals (i.e., the advective tendencies of $\langle\bar{h}\rangle$ ) are summarized, in Fig. 10. These calculations show that overall the total circulation acts to reduce the column moist static energy variance. Deep (top heavy) and shallow circulations thus work against one another (Fig. 10a), with the horizontal component of the shallow circulation playing the most important role in regions of large $\langle\bar{h}\rangle$ (Fig. 10b) and the vertical component of the circulation being more important in regions of small $\langle\bar{h}\rangle$ (Fig. 10c). This analysis suggests that a distinguishing aspect of convective selfaggregation, namely, the development of a shallow circulation to support the convective self-aggregation, is also important for sustaining the observed structure of the atmosphere over the BCO, and perhaps the Atlantic ITCZ more broadly. This suggests that a model's ability to represent convective self-aggregation, and in particular the development of a radiatively driven shallow circulation to support this process, may be important in its adequate representation of the ITCZ, at least in conditions similar to those sampled over the BCO.

\section{Radiative forcing of circulations in moisture space}

Large-scale overturning circulations in the tropics are often thought to be associated with a top-heavy heating profile. Such a heating profile can be attributed to diabatic processes associated with deep convection, for instance, stratiform rain formation and cloud radiative effects (Houze 1982). On scales larger than a few hundred kilometers, where cold pools are efficient (Jeevanjee and Romps 2013), and in the absence of strong surface temperature gradients (Hohenegger and Stevens 2018), radiative and convective heating anomalies across moisture space are thought to be important in driving shallow circulations. Here we explore to what extent the shallow circulation that we infer from the data can be attributed to the anomalies measured in the moisture space defined by the BCO observations. As in section 4 the circulation is estimated by mapping vertical velocity profiles into a streamfunction. In this section, however, the vertical velocity profiles are calculated using the weak temperature gradient approximation (Sobel and Bretherton 2000) in combination with the radiative heating rates calculated from the observed atmospheric state.

To do so, we calculate the clear- and all-sky heating rates for the different portions of moisture space using the PSrad flavor of the rapid radiative transfer model (Pincus and Stevens 2013; Mlawer et al. 1997). In calculating radiative heating rates the condensate loading within clouds is not directly measured, but estimated based on condensate lapse rates deduced by LES. However, because this is uncertain we focus on the clear-sky heating-rate anomalies driven by differences in water vapor across moisture space. To capture both the diurnal cycle as well as the annual cycle in an average 

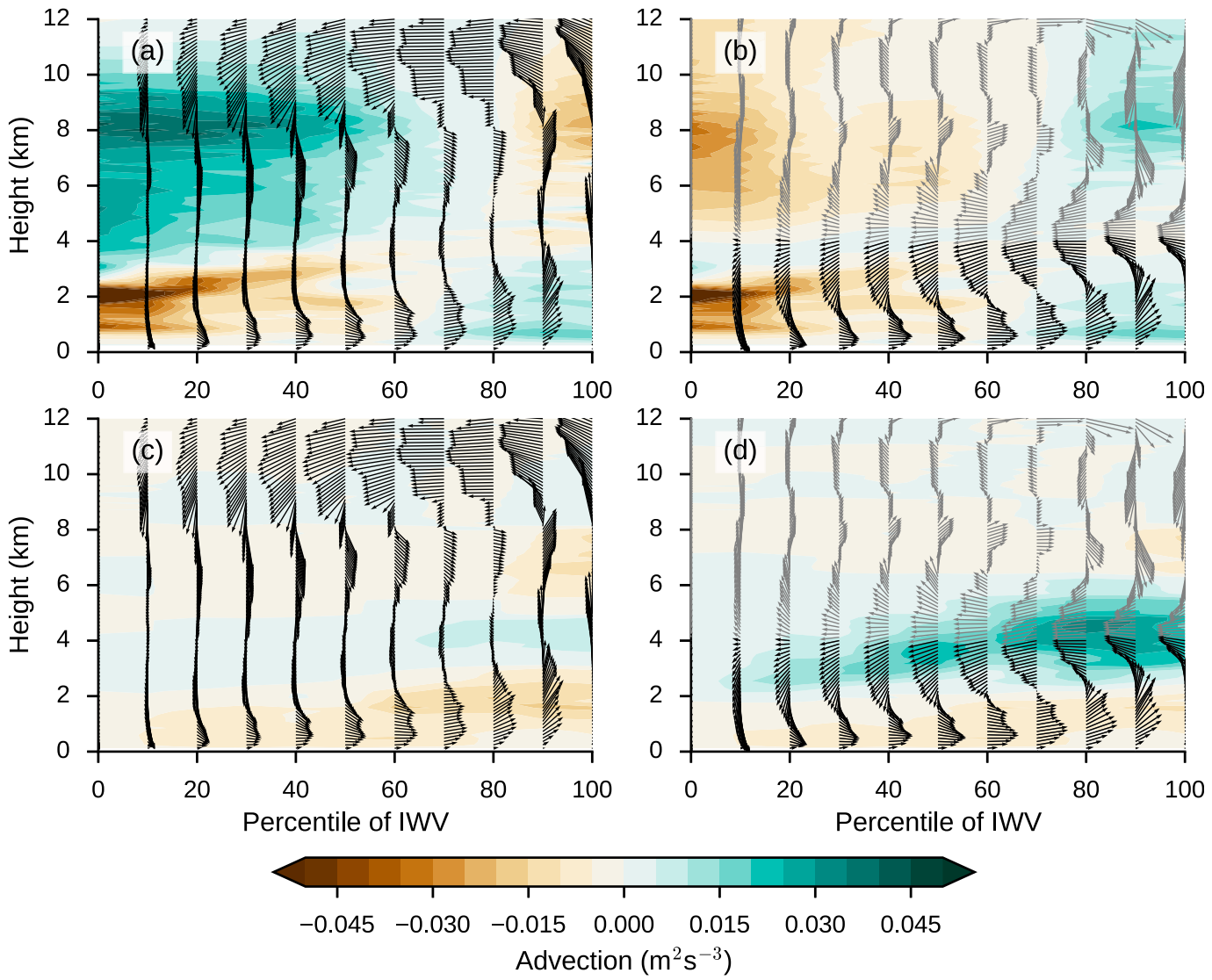

FIG. 9. Moist static energy advection by the (a),(c) overall circulation and (b),(d) shallow circulation. The contribution is split into the (a),(b) vertical and (c),(d) horizontal components. MSE transport to the dry regions is defined as positive advection. Wind arrows show the circulation pattern but are only for visualization purposes as their components are not to scale contingent on the construction of the moisture space cross section. Winds that are used to calculate advection (black) are separated from the remnants of the circulation decomposition (gray).

sense, we have chosen a solar zenith angle of $41^{\circ}$ following Cronin (2014) and adapted the solar constant accordingly $\left(591.76 \mathrm{~W} \mathrm{~m}^{-2}\right)$, so that the climatological net radiation at the top of the atmosphere is correct. We further assume a surface albedo of 0.05 . For the longwave, we use a tropical standard atmosphere to represent the trace gases $\mathrm{CO}_{2}, \mathrm{O}_{3}, \mathrm{~N}_{2} \mathrm{O}, \mathrm{CO}$, and $\mathrm{CH}_{4}$ (Anderson et al. 1986). To calculate the vertical motion
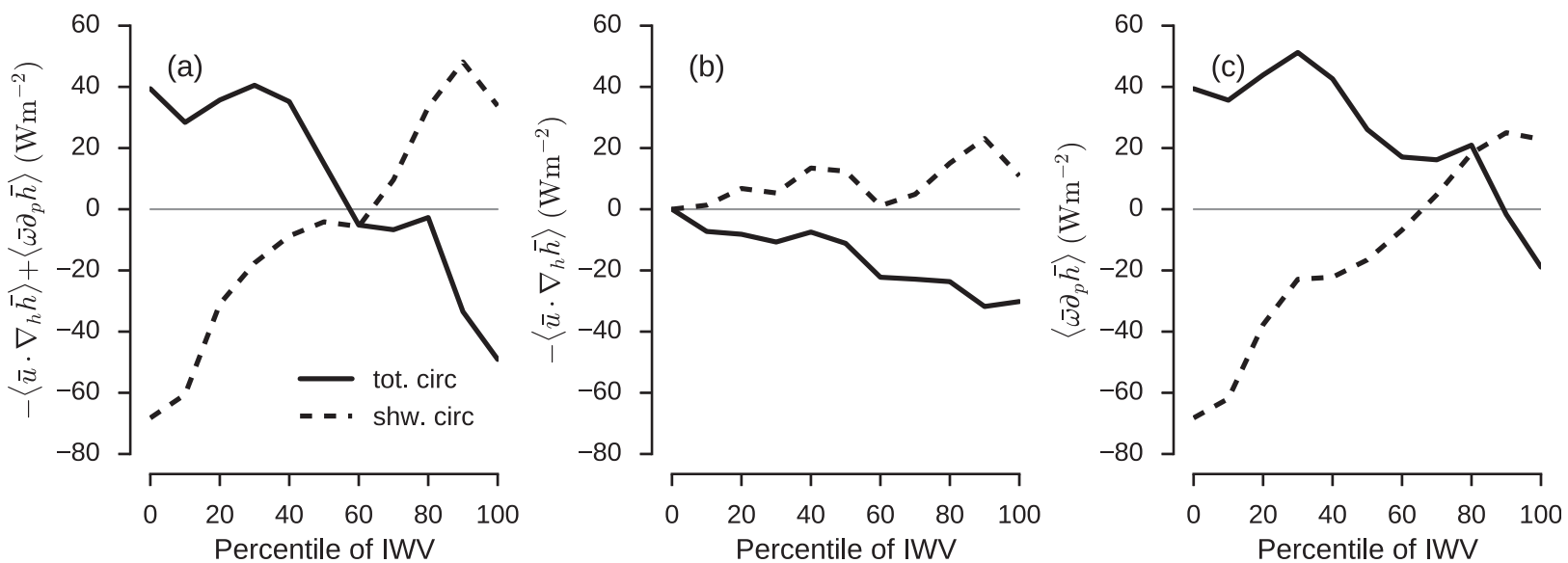

FIG. 10. Moist static energy advection budgets for the (a) total advection, (b) horizontal advection, and (c) vertical advection. 

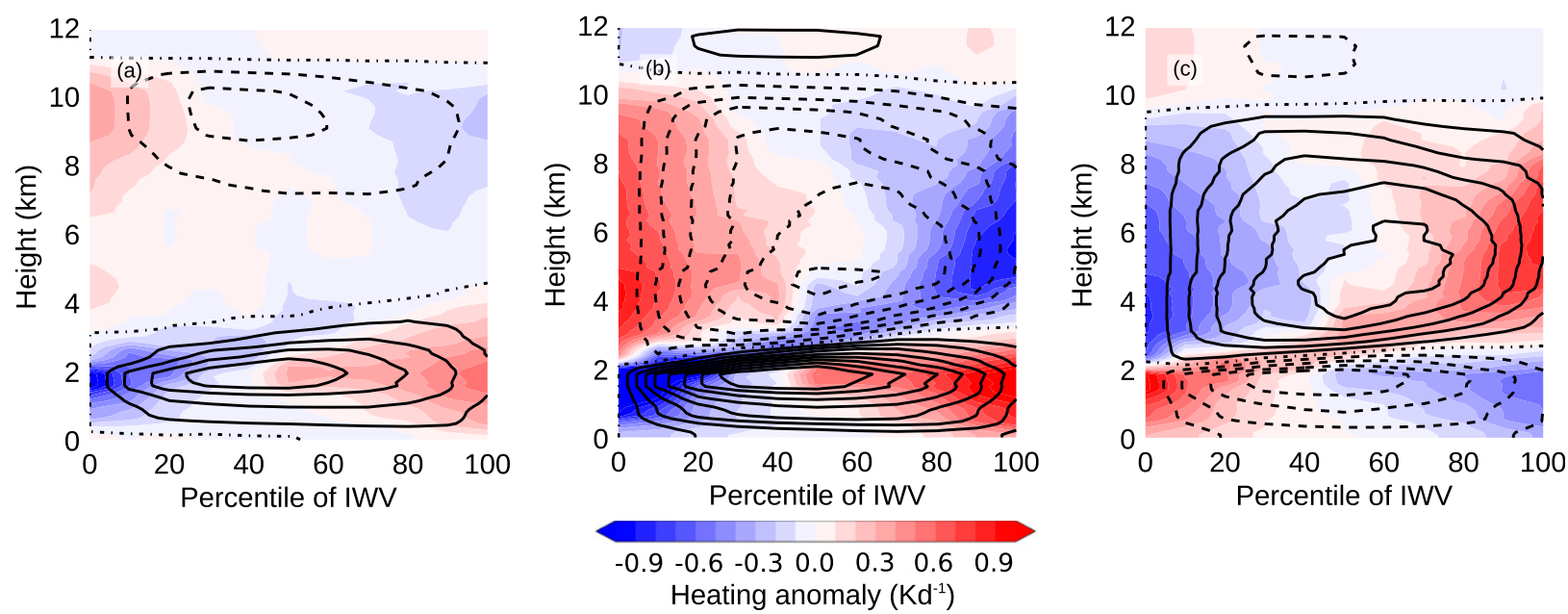

Heating anomaly $\left(\mathrm{Kd}^{-1}\right)$

FIG. 11. Radiatively driven circulation with its causing clear-sky heating anomalies for (a) net, (b) longwave, and (c) shortwave radiation. The streamfunction is drawn with an interval of $0.1 \mathrm{~g} \mathrm{~m}^{-2} \mathrm{~s}^{-1}$ and has a net maximum in (a) of $0.5 \mathrm{~g} \mathrm{~m}^{-2} \mathrm{~s}^{-1}$.

$\omega_{\text {rad }}$ we normalize the heating rates $Q$ by the atmospheric stability $S$ in each column:

$$
\omega_{\mathrm{rad}}(p)=Q_{\mathrm{rad}}^{\prime} S^{-1}
$$

We use heating anomalies $Q^{\prime}$ relative to the mean at any level, as the mean heating will not drive a circulation. The stability is given as $S=\Pi(\partial \theta / \partial p)$, where $\theta$ denotes potential temperature, $p$ is pressure, and $\Pi$ is the nondimensional pressure-or Exner function. Because the stability of the free troposphere is largely set by the moist adiabat, and does not vary greatly through the course of the year, for these calculations we use climatological values of $S$ from the JRA-55. Within the mixed layer the weak temperature gradient approximation is not valid; however, an assumed constant divergence (Bony et al. 2017) below $700 \mathrm{~m}$ would not change the general picture of the return flow.

Water vapor differences across moisture space are very effective in driving a shallow circulation similar to that which has been isolated in the combined reanalysis (Fig. 7). This is shown in Fig. 11a, which superimposes the weak temperature gradient approximation circulation response to the clear-sky heating response on the clear-sky heating anomaly. In addition to the net radiative heating the different contributions from the shortwave and longwave irradiances are shown separately. The figure illustrates pronounced clear-sky heating gradients, particularly in the lower troposphere, mostly within the shallow cloud (or trade winds) layer below 2-3 km, a height just below the maximum differences in the absolute humidities (as seen in Fig. 7).

Physically the radiative heating/cooling anomalies can be interpreted from the perspective of the anomalous moisture in the very dry atmosphere, and the cooling to space approximation (Mapes and Zuidema 1996; Thomas and Stamnes 1999). The moisture deficit associated with the very dry atmosphere above $2 \mathrm{~km}$ reduces the downwelling longwave from that layer, which leads to reduced cooling there. Less downwelling longwave radiation into the lower layer results, however, in a greater net radiative flux divergence out of the lower moist layer and thus enhances the cooling there, forming the vertical dipole in heating and cooling evident in Fig. 11b. The pattern in the moist column can be understood analogously. Shortwave radiation acts in many respects similarly but opposite to the longwave (Fig. 11c). This is because absorption is primarily associated with the absolute humidity. The dry free troposphere and lack of clouds in the dry columns concentrates shortwave heating in the boundary layer, thereby partially offsetting the longwave cooling. In the lower atmosphere (below $3 \mathrm{~km}$ ) the effects of the longwave heating are, however, dominant, whereas higher up the two effects roughly cancel each other.

The vertical motion field required to balance these heating anomalies imply a shallow circulation flowing toward the moist columns near the surface, with a return branch from the moist to the dry columns between 2 and $4 \mathrm{~km}$. This is shown by the streamfunction for the case of the net heating rate and circulation (contour lines) in Fig. 11a. The circulation driven by the net clear-sky radiative heating anomalies can explain $25 \%-30 \%$ of the total shallow circulation we diagnose. Further support of the shallow circulation could arise for example from low-level convective heating anomalies as shown by Holloway and Woolnough (2016). 
Comparison of the figures shows that the circulation can mostly be attributed to the effects of longwave radiation. Longwave and shortwave cloud radiative effects act in a similar sense to their clear-sky counterparts, also with the longwave component dominating so that they substantially strengthen the net radiatively driven circulation.

Another factor, which needs further investigations, is the cloud radiative effect. Low clouds in the dry region enhance the cooling at the cloud top, which is balanced by an increased subsidence warming. The downward motion on the dry end is strengthened as is (through continuity) the whole circulation. Differences between the longwave and shortwave are also suggestive of a diurnal cycle in the vertical motion, with enhanced lowlevel convergence into the warm columns during the night, and a reverse circulation aloft during the day (Ruppert and Johnson 2016). Overall the mean circulation in Fig. 11a is similar to what has been seen in studies, on much smaller scales, of convective selfaggregation. It suggests that many of the processes that are operative in these very idealized simulations may also play a role in strengthening and localizing deep convection within the ITCZ, reminiscent in some sense of arguments developed by Nigam (1997) on a yet larger scale in connection with the radiative effect of stationary eddies in the tropics.

\section{Conclusions and outlook}

In this study we use observations of the tropical atmosphere to explore the dynamics of the tropical atmosphere in moisture space. For the observations we use measurements made at the Barbados Cloud Observatory, the only advanced surface-based remote sensing meteorological station in the broader tropics. Raman lidar measurements provide water vapor profiling through the tropical atmosphere, and cloud radar provides the vertical distribution of clouds. These measurements are complemented by soundings, and reanalyses for the purposes of diagnosing temperature profiles and vertical motion, respectively, and handling missing values, for instance above optically thick clouds. The use of the BCO measurements for this purpose are advantageous because they locate on the edge of the intertropical convergence zone (ITCZ), and so sample its seasonal migration; from deep convection in a very moist atmosphere characteristic of the inner ITCZ mainly in its wet season, and much drier conditions, characteristic of the North Atlantic trades, primarily during its dry season. Compared to Holloway et al. (2017, their Fig. 6b), a somewhat broader distribution of moisture space is sampled over sea surface temperatures between about 300 and $303 \mathrm{~K}$. Compared to Yin and Albrecht (2000), who analyzed 916 soundings from the First Global Atmospheric Research Program Global Experiment $\left(10^{\circ} \mathrm{S}-15^{\circ} \mathrm{N}, 160^{\circ}-90^{\circ} \mathrm{W}\right.$, ) a much greater variability is sampled, but some of the general characteristics that we observe, with the largest average difference between the moist and dry regimes of $5 \mathrm{~g} \mathrm{~kg}^{-1}$ just above a shallow marine layer, agree well with that study.

The structure of the atmosphere over the $\mathrm{BCO}$ is, when plotted in moisture space, very similar to what is seen in self-aggregated simulations of radiative-convective equilibrium (RCE; Wing et al. 2017), despite the large difference in scale between the cloud-resolving simulations of RCE and the moisture space observations of the seasonal migration of the ITCZ. Dry columns locate over somewhat colder SSTs and thus have slightly less boundary layer moisture, but are, overall, distinguished from regions of high integrated water vapor, by their pronounced dryness in a layer between 2 and $5 \mathrm{~km}$ topping a moist marine layer. Low-level cloudiness is pronounced across the entirety of moisture space, but maximizes in regions of low integrated water vapor. Deep clouds, which penetrate through the depth of the troposphere, are most evident in the very moistest columns. High clouds are more widespread, but also concentrate over deep moist layers. The reason for this omnipresence of low and high clouds compared to simulations, for example., Holloway and Woolnough (2016, their Figs. 7 and 8), needs further investigation. Currently, the amount of high and low clouds in simulations of RCE is known to be sensitive to how the simulations are configured (i.e., microphysical choices and resolution).

From a moisture space perspective the structure of the tropical atmosphere in the region of the western Atlantic ITCZ is very similar to a convectively selfaggregated atmosphere in simulations of RCE.

The circulation in moisture space, which is derived from different reanalysis products, is also similar to what is found for the self-aggregated state in simulations of RCE. Despite surprisingly large differences among the reanalyses, a pronounced signature of a shallow (lower tropospheric) circulation robustly emerges. Analysis of the moist static energy budget shows that this circulation ventilates the low static energy found in the lower midtroposphere (near $4 \mathrm{~km}$ ) from the moist columns, and imports high near-surface moist static energy, and thereby increases the contrast, or variance, in integrated water vapor. With the exception of an early study by Jeevanjee and Romps (2013), wherein it was argued that two-dimensional simulations of the shallow circulations act to weaken the aggregation after it emerges, 
simulations of radiative-convective equilibrium identify, as does our analysis, shallow circulations that support the convective self-aggregation processes. In our analysis, as in many of the idealized simulations, this circulation appears to be substantially driven by radiative heating anomalies across moisture space, particularly the contrast between a very dry free troposphere and a shallow cloud moist layer in the dry regions. Modeling work by Nishant et al. (2016) reached similar conclusions.

Our analysis cannot adjudicate whether shallow circulations driven by differential radiative heating across moisture space are more or less important than the diabatic processes that some studies have hypothesized underpin convective self-aggregation. Examples of the latter include surface-wind feedbacks, high-cloud radiative effects, and moisture-convection feedbacks. The Barbados Cloud Observatory data do, however, suggest that shallow circulations, driven in part by differential radiative cooling, are present in the tropical atmosphere and important for sustaining the contrast between the maritime trades and the Atlantic ITCZ. These findings fit well with previous observationally based studies, which have also argued for the importance of shallow circulations in explaining regions of moisture convergence and convection in the tropical atmosphere (Back and Bretherton 2009; Zhang et al. 2004, 2008; Yokoyama et al. 2014). Our analysis goes one step further, however, as by performing the analysis in moisture space it suggests that mechanisms emerging in idealized simulations of radiative-convective equilibrium may also be relevant to explaining large-scale features of the maritime tropics.

The idea that mechanisms underpinning convective self-aggregation, as known from modeling studies, might be important for understanding tropical convection more generally would be strengthened if the observations we analyzed could be reproduced on a smaller scale, and over shorter periods in time. This might become possible by compositing over events as more observations are collected at the BCO or through the establishment of a small network of observing stations or a ship array as suggested by Holloway et al. (2017). The observational case for self-aggregation, and a better quantification of the relative role of the processes underpinning it, would also be strengthened if large-scale vertical motion could be directly measured, rather than taken from the reanalyses. Both the need to observe the local thermodynamic structure of the atmosphere around regions of developing convection, and the need to measure large-scale vertical motion in this (moisture) space, could be addressed with a single aircraft, particularly given the recent demonstration [as part of the
2016 Next Generation Airborne Remote Sensing for Validation Studies (NARVAL2) campaign] that vertical motion can be directly inferred from dropsonde-derived divergence measurements. However, a combination of approaches, as for instance is being developed to study shallow convection in the winter trades (Bony et al. 2017), but applied in and around regions of deep convection, offers the most exciting opportunity to build on the point measurements as analyzed here, so as to advance understanding of how convection interacts with its environment and the role of convective organization in these interactions.

Acknowledgments. Cathy Hohenegger is thanked for her input and suggestions through the course of this study. Dagmar Fläschner and Julia Windmiller are thanked for their invaluable comments on an earlier draft. Johannes Kiliani and Ilya Serikov are thanked for an early release of calibrated water vapor data from the Raman lidar. The BCO data are freely available to the broader community upon request. NCEP-Reanalysis 2 data have been provided by the NOAA/OAR/ESRL PSD, Boulder, Colorado, from their website (http://www.esrl. noaa.gov/psd/). In addition, Chris Holloway and two anonymous reviewers are thanked for their comments, which helped to improve and clarify the paper.

\section{REFERENCES}

Anderson, G. P., S. A. Clough, F. X. Kneizys, J. H. Chetwynd, and E. P. Shettle, 1986: AFGL atmospheric constituent profiles (0-120km). Tech. Rep. AFGL-TR-86-0110, Environmental Research Paper 954, Air Force Geophysics Laboratory, 46 pp., http://www.dtic.mil/dtic/tr/fulltext/u2/a175173.pdf.

Arnold, N. P., and D. A. Randall, 2015: Global-scale convective aggregation: Implications for the Madden-Julian Oscillation. J. Adv. Model. Earth Syst., 7, 1499-1518, https://doi.org/ 10.1002/2015MS000498.

Back, L. E., and C. S. Bretherton, 2006: Geographic variability in the export of moist static energy and vertical motion profiles in the tropical Pacific. Geophys. Res. Lett., 33, L17810, https:// doi.org/10.1029/2006GL026672.

_ and - 2009: A simple model of climatological rainfall and vertical motion patterns over the tropical oceans. J. Climate, 22, 6477-6497, https://doi.org/10.1175/2009JCLI2393.1.

Becker, T., B. Stevens, and C. Hohenegger, 2017: Imprint of the convective parameterization and sea-surface temperature on large-scale convective self-aggregation. J. Adv. Model. Earth Syst., 9, 1488-1505, https://doi.org/10.1002/2016MS000865.

Bony, S., and Coauthors, 2015: Clouds, circulation and climate sensitivity. Nat. Geosci., 8, 261-268, https://doi.org/10.1038/ ngeo2398.

- B. Stevens, D. Coppin, T. Becker, K. A. Reed, A. Voigt, and B. Medeiros, 2016: Thermodynamic control of anvil cloud amount. Proc. Natl. Acad. Sci. USA, 113, 8927-8932, https:// doi.org/10.1073/pnas.1601472113.

_- and Coauthors, 2017: EUREC ${ }^{4} \mathrm{~A}$ : A field campaign to elucidate the couplings between clouds, convection and 
circulation. Surv. Geophys., 38, 1529-1568, https://doi.org/ 10.1007/s10712-017-9428-0.

Bretherton, C. S., P. N. Blossey, and M. Khairoutdinov, 2005: An energy-balance analysis of deep convective self-aggregation above uniform SST. J. Atmos. Sci., 62, 4273-4292, https:// doi.org/10.1175/JAS3614.1.

Coppin, D., and S. Bony, 2015: Physical mechanisms controlling the initiation of convective self-aggregation in a General Circulation Model. J. Adv. Model. Earth Syst., 7, 2060-2078, https://doi.org/10.1002/2015MS000571.

—_, and —_, 2017: Internal variability in a coupled general circulation model in radiative-convective equilibrium. $G e-$ ophys. Res. Lett., 44, 5142-5149, https://doi.org/10.1002/ 2017GL073658.

Craig, G. C., and J. M. Mack, 2013: A coarsening model for selforganization of tropical convection. J. Geophys. Res., 118, 8761-8769, https://doi.org/10.1002/jgrd.50674.

Cronin, T. W., 2014: On the choice of average solar zenith angle. J. Atmos. Sci., 71, 2994-3003, https://doi.org/10.1175/ JAS-D-13-0392.1.

Dee, D. P., and Coauthors, 2011: The ERA-Interim reanalysis: Configuration and performance of the data assimilation system. Quart. J. Roy. Meteor. Soc., 137, 553-597, https://doi.org/ 10.1002/qj.828.

Fläschner, D., 2016: Intermodel spread in global and tropical precipitation changes. Ph.D. thesis, Universität Hamburg, Max-Planck-Institut für Meteorologie, 116 pp., http:// pubman.mpdl.mpg.de/pubman/item/escidoc:2321127/component/ escidoc:2321126/WEB_BzE_183.pdf.

Hersbach, H., and D. Dee, 2016: ERA5 reanalysis is in production. ECMWF Newsletter, No. 147, ECMWF, Reading, United Kingdom, p. 7, https://www.ecmwf.int/sites/default/files/elibrary/ 2016/16299-newsletter-no147-spring-2016.pdf.

Hohenegger, C., and B. Stevens, 2016: Coupled radiative convective equilibrium simulations with explicit and parameterized convection. J. Adv. Model. Earth Syst., 8, 1468-1482, https:// doi.org/10.1002/2016MS000666.

_ and _ 2018: The role of the permanent wilting point in controlling the spatial distribution of precipitation. Proc. Natl. Acad. Sci. USA, 115, 5692-5697, https://doi.org/10.1073/ pnas. 1718842115 .

Holloway, C. E., and S. J. Woolnough, 2016: The sensitivity of convective aggregation to diabatic processes in idealized radiative-convective equilibrium simulations. J. Adv. Model. Earth Syst., 8, 166-195, https://doi.org/10.1002/2015MS000511.

— , A. A. Wing, S. Bony, C. Muller, H. Masunaga, T. S. L'Ecuyer, D. D. Turner, and P. Zuidema, 2017: Observing convective aggregation. Surv. Geophys., 38, 1199-1236, https://doi.org/ 10.1007/s10712-017-9419-1.

Houze, R. A., Jr., 1982: Cloud clusters and large-scale vertical motions in the tropics. J. Meteor. Soc. Japan, 60, 396-410, https://doi.org/10.2151/jmsj1965.60.1_396.

_ 2 2004: Mesoscale convective systems. Rev. Geophys., 42, RG4003, https://doi.org/10.1029/2004RG000150.

Japan Meteorological Agency, 2013: JRA-55: Japanese 55-year Reanalysis, daily 3-hourly and 6-hourly data. Research Data Archive, National Center for Atmospheric Research, Computational and Information Systems Laboratory, Boulder, CO, accessed 19 May 2016, https://doi.org/10.5065/ D6HH6H41.

Jeevanjee, N., and D. M. Romps, 2013: Convective self-aggregation, cold pools, and domain size. Geophys. Res. Lett., 40, 994-998, https://doi.org/10.1002/grl.50204.
Kanamitsu, M., W. Ebisuzaki, J. Woollen, S.-K. Yang, J. J. Hnilo, M. Fiorino, and G. L. Potter, 2002: NCEP-DOE AMIP-II Reanalysis (R-2). Bull. Amer. Meteor. Soc., 83, 1631-1643, https://doi.org/10.1175/BAMS-83-11-1631.

Kobayashi, S., and Coauthors, 2015: The JRA-55 Reanalysis: General specifications and basic characteristics. J. Meteor. Soc. Japan, 93, 5-48, https://doi.org/10.2151/jmsj.2015-001.

Madden, R. A., and P. R. Julian, 1994: Observations of the 4050-day tropical oscillation-A review. Mon. Wea. Rev., 122, 814-837, https://doi.org/10.1175/1520-0493(1994)122<0814: OOTDTO $>2.0 . \mathrm{CO} ; 2$

Mapes, B. E., and R. A. Houze, 1993: Cloud clusters and superclusters over the oceanic warm pool. Mon. Wea. Rev., 121, 1398-1416, https://doi.org/10.1175/1520-0493(1993)121<1398: CCASOT $>2.0 . \mathrm{CO} ; 2$

— , and P. Zuidema, 1996: Radiative-dynamical consequences of dry tongues in the tropical troposphere. J. Atmos. Sci., 53, 620-638, https://doi.org/10.1175/1520-0469(1996)053<0620: RDCODT $>2.0 . \mathrm{CO} ; 2$.

Mlawer, E. J., S. J. Taubman, P. D. Brown, M. J. Iacono, and S. A. Clough, 1997: Radiative transfer for inhomogeneous atmospheres: RRTM, a validated correlated-k model for the longwave. J. Geophys. Res., 102, 16 663-16682, https://doi.org/ 10.1029/97JD00237.

Muller, C. J., and I. M. Held, 2012: Detailed investigation of the self-aggregation of convection in cloud-resolving simulations. J. Atmos. Sci., 69, 2551-2565, https://doi.org/10.1175/ JAS-D-11-0257.1.

- and S. Bony, 2015: What favors convective aggregation and why? Geophys. Res. Lett., 42, 5626-5634, https://doi.org/ 10.1002/2015GL064260.

Nakazawa, T., 1988: Tropical super clusters within intraseasonal variations over the western Pacific. J. Meteor. Soc. Japan, 66, 823-839, https://doi.org/10.2151/jmsj1965.66.6_823.

Naumann, A. K., B. Stevens, C. Hohenegger, and J. P. Mellado, 2017: A conceptual model of a shallow circulation induced by prescribed low-level radiative cooling. J. Atmos. Sci., 74, 31293144, https://doi.org/10.1175/JAS-D-17-0030.1.

Neelin, J. D., and I. M. Held, 1987: Modeling tropical convergence based on the moist static energy budget. Mon. Wea. Rev., 115, 3-12, https://doi.org/10.1175/1520-0493(1987)115<0003: MTCBOT $>2.0 . \mathrm{CO} ; 2$.

Nigam, S., 1997: The annual warm to cold phase transition in the eastern equatorial Pacific: Diagnosis of the role of stratus cloud-top cooling. J. Climate, 10, 2447-2467, https://doi.org/ 10.1175/1520-0442(1997)010<2447:TAWTCP >2.0.CO;2.

Nishant, N., S. C. Sherwood, and O. Geoffroy, 2016: Radiative driving of shallow return flows from the ITCZ. $J$. $A d v$. Model. Earth Syst., 8, 831-842, https://doi.org/10.1002/ 2015MS000606.

Nuijens, L., I. Serikov, L. Hirsch, K. Lonitz, and B. Stevens, 2014: The distribution and variability of low-level cloud in the North Atlantic trades. Quart. J. Roy. Meteor. Soc., 140, 2364-2374, https://doi.org/10.1002/qj.2307.

Pauluis, O., A. Czaja, and R. Korty, 2010: The global atmospheric circulation in moist isentropic coordinates. J. Climate, 23, 3077-3093, https://doi.org/10.1175/2009JCLI2789.1.

Pincus, R., and B. Stevens, 2013: Paths to accuracy for radiation parameterizations in atmospheric models. J. Adv. Model. Earth Syst., 5, 225-233, https://doi.org/10.1002/jame.20027.

Raymond, D. J., 2000: The Hadley circulation as a radiativeconvective instability. J. Atmos. Sci., 57, 1286-1297, https:// doi.org/10.1175/1520-0469(2000)057<1286:THCAAR>2.0.CO;2. 
, S. L. Sessions, A. H. Sobel, and Z. Fuchs, 2009: The mechanics of gross moist stability. J. Adv. Model. Earth Syst., 1 (3), https://doi.org/10.3894/JAMES.2009.1.9.

Rienecker, M. M., and Coauthors, 2011: MERRA: NASA's Modern-Era Retrospective Analysis for Research and Applications. J. Climate, 24, 3624-3648, https://doi.org/10.1175/ JCLI-D-11-00015.1.

Rotunno, R., J. B. Klemp, and M. L. Weisman, 1988: A theory for strong, long-lived squall lines. J. Atmos. Sci., 45, 463-485, https://doi.org/10.1175/1520-0469(1988)045<0463: ATFSLL $>2.0 . \mathrm{CO} ; 2$.

Ruppert, J. H., and R. H. Johnson, 2016: On the cumulus diurnal cycle over the tropical warm pool. J. Adv. Model. Earth Syst., 8, 669-690, https://doi.org/10.1002/2015MS000610.

Sobel, A. H., and C. S. Bretherton, 2000: Modeling tropical precipitation in a single column. J. Climate, 13, 4378-4392, https:// doi.org/10.1175/1520-0442(2000)013<4378:MTPIAS >2.0.CO;2.

Stevens, B., and Coauthors, 2016: The Barbados Cloud Observatory: Anchoring investigations of clouds and circulation on the edge of the ITCZ. Bull. Amer. Meteor. Soc., 97, 787-801, https://doi.org/10.1175/BAMS-D-14-00247.1.

- H. Brogniez, C. Kiemle, J.-L. Lacour, C. Crevoisier, and J. Kiliani, 2017: Structure and dynamical influence of water vapor in the lower tropical troposphere. Surv. Geophys., 38, 1371-1397, https://doi.org/10.1007/s10712-017-9420-8.

Thomas, G. E., and K. Stamnes, 1999: Radiative Transfer in the Atmosphere and Ocean. Cambridge Atmospheric and Space Science Series, Cambridge University Press, 548 pp., https:// doi.org/10.1017/CBO9780511613470.

Tobin, I., S. Bony, and R. Roca, 2012: Observational evidence for relationships between the degree of aggregation of deep convection, water vapor, surface fluxes, and radiation. J. Climate, 25, 6885-6904, https://doi.org/10.1175/JCLI-D-11-00258.1.
, C. E. Holloway, J.-Y. Grandpeix, G. Sèze, D. Coppin, S. J. Woolnough, and R. Roca, 2013: Does convective aggregation need to be represented in cumulus parameterizations? J. Adv. Model. Earth Syst., 5, 692-703, https://doi.org/10.1002/jame.20047.

Tompkins, A. M., 2001: Organization of tropical convection in low vertical wind shears: The role of water vapor. J. Atmos. Sci., 58, 529-545, https://doi.org/10.1175/1520-0469(2001)058<0529: OOTCIL $>2.0 . \mathrm{CO} ; 2$.

Wing, A. A., and K. A. Emanuel, 2014: Physical mechanisms controlling self-aggregation of convection in idealized numerical modeling simulations. J. Adv. Model. Earth Syst., 6, 59-74, https://doi.org/10.1002/2013MS000269.

— , and T. W. Cronin, 2016: Self-aggregation of convection in long channel geometry. Quart. J. Roy. Meteor. Soc., 142, 1-15, https://doi.org/10.1002/qj.2628.

_ , K. Emanuel, C. E. Holloway, and C. Muller, 2017: Convective self-aggregation in numerical simulations: A review. Surv. Geophys., 38, 1173-1197, https://doi.org/10.1007/s10712-017-9408-4.

Yin, B., and B. A. Albrecht, 2000: Spatial variability of atmospheric boundary layer structure over the eastern equatorial Pacific. J. Climate, 13, 1574-1592, https://doi.org/10.1175/ 1520-0442(2000)013<1574:SVOABL>2.0.CO;2.

Yokoyama, C., E. J. Zipser, and C. Liu, 2014: TRMM-observed shallow versus deep convection in the eastern Pacific related to large-scale circulations in reanalysis datasets. J. Climate, 27, 5575-5592, https://doi.org/10.1175/JCLI-D-13-00315.1.

Zhang, C., M. McGauley, and N. A. Bond, 2004: Shallow meridional circulation in the tropical eastern Pacific. J. Climate, 17, 133-139, https://doi.org/10.1175/1520-0442(2004)017<0133: SMCITT $>2.0 . \mathrm{CO} ; 2$.

— D. S. Nolan, C. D. Thorncroft, and H. Nguyen, 2008: Shallow meridional circulations in the tropical atmosphere. J. Climate, 21, 3453-3470, https://doi.org/10.1175/2007JCLI1870.1. 